\title{
Comparison of clonidine and methyldopa on blood pressure and side effects in hypertensive patients
}

\author{
M. Roberto Putzeys, M.D. \\ S. W. Hoobler, M.D. \\ Ann Arbor, Mich.
}

\begin{abstract}
Olonid onidine hydrochloride (Catapres) represents a new type of antihypertensive agent which acts to reduce blood pressure by central inhibition of sympathetic vasomotor and cardioexcitatory stimuli. ${ }^{1,2}$ We have previously demonstrated its antihypertensive effectiveness particularly when combined with a diuretic. ${ }^{3}$ The drug has been shown to have long-term effectiveness in the treatment of severe hypertension and sufficient potency to replace guanethidine. Sedation, constipation, and dry mouth are its chief side effects; they tend to decrease with the passage of time and are less objectionable than the fatigue and postural syncope frequently seen with guanethidine. ${ }^{4}$

Clonidine is also useful in smaller doses in the treatment of less severe forms of hypertension, where other antihypertensive drugs such as alpha methyldopa may also be effective.

The purpose of the present study is to compare these two drugs at a fixed dosage, both concerning their hypotensive effectiveness in patients with moderately severe hypertension and also concerning side effects produced by each agent when the blood pressure is lowered to a comparable degree.
\end{abstract}

\begin{abstract}
Mothods
Patients were selected who exhibited moderately severe essential hypertension as defined by a recumbent diastolic blood pressure between 90 and $120 \mathrm{~mm}$. $\mathrm{Hg}$ on diuretic therapy alone. As a check on changes we expected to observe in the casual clinic blood pressures, they were also instructed in the technique of recording their own blood pressures at home.

Out of 20 patients who originally agreed to participate, 8 werc climinated, 5 because their average blood pressure fell below $90 \mathrm{~mm}$. Hg during the control period, one because of difficulty in attending the clinic, and 2 patients because of intolerance to methyldopa (nausea and vomiting). These 2 were subsequently given clonidine without the development of severe side effects, but they are not considered in the results to be reported.

At each scheduled outpatient visit approximately 2 to 4 hours after the morning dose of the drugs had been ingested, the casual recumbent and standing blood pressures and pulse rate were taken by the clinic nurse. The patients also brought in a report of their twice daily home blood pressure readings over the interval. At the
\end{abstract}

\footnotetext{
From the Department of Internal Medicine, Hypertension Section, University of Michigan Medical Center, Ann Arbor, Mich. 48104.

Supported by National Institutes of Health Grant 5 P11-GM 15559.

Received for publication June 18, 1971.

Requests for reprints to: Sibley W. Hoobler, M.D., R6669 Kresge Medical Research Building, University of Michigan Medical Center, Aun Arbor, Mich. 48104.
} 
Table I. Clinic recumbent blood pressure response and side effects at the end of 3 months of treatment

\begin{tabular}{|c|c|c|c|c|c|c|c|c|c|}
\hline \multirow{3}{*}{ Patient* } & \multicolumn{3}{|c|}{ Recumbent blood pressure } & \multicolumn{6}{|c|}{ Side effects at third month } \\
\hline & \multirow{2}{*}{ "Control" $\uparrow$} & \multicolumn{2}{|c|}{ Change after 3 months of: } & \multicolumn{2}{|c|}{ Sedation } & \multicolumn{2}{|c|}{ Constipation } & \multicolumn{2}{|c|}{ Dry mouth } \\
\hline & & $M e$ & $\mathrm{Cl}$ & $M e$ & $\mathrm{Cl}$ & $M e$ & $\mathrm{Cl}$ & $M e$ & $\mathrm{Cl}$ \\
\hline $1 \mathrm{Me}$ & $185 / 119$ & $-48 /-37$ & $-69 /-36$ & 0 & $1+$ & 0 & 0 & 0 & $2+$ \\
\hline $2 \mathrm{Cl}$ & $200 / 99$ & $-62 /-18$ & $-60 /-21$ & 0 & $1+$ & 0 & 0 & 0 & $2+$ \\
\hline $3 \mathrm{Cl}$ & $167 / 106$ & $-30 /-16$ & $-55 /-25$ & 0 & $1+$ & 0 & 0 & $1+$ & $1+$ \\
\hline $4 \mathrm{Me}$ & $207 / 105$ & $-34 /-12$ & $-27 /-15$ & $2+$ & $1+$ & 0 & $1+$ & 0 & $2+$ \\
\hline $5 \mathrm{Me}$ & $177 / 108$ & $-25 /-8$ & $-32 /-19$ & $1+$ & $2+$ & 0 & 0 & 0 & $2+$ \\
\hline $6 \mathrm{Me}$ & $153 / 91$ & $-25 /-11$ & $-8 /-8$ & $1+$ & $3+$ & 0 & $1+$ & $1+$ & $2+$ \\
\hline $7 \mathrm{Cl}$ & $163 / 107$ & $-24 /-11$ & $-16 /+4$ & 0 & $1+$ & 0 & 0 & 0 & $1+$ \\
\hline $8 \mathrm{Cl}$ & $152 / 109$ & $-16 /-9$ & $-12 /-9$ & 0 & $3+$ & 0 & 0 & 0 & $1+$ \\
\hline $9 \mathrm{Cl}$ & $161 / 107$ & $-14 /-5$ & $-23 /-23$ & 0 & $1+$ & $1+$ & $2+$ & 0 & $1+$ \\
\hline $10 \mathrm{Me}$ & $166 / 117$ & $-12 /-2$ & $-14 /--18$ & 0 & 0 & 0 & 0 & $1+$ & $1+$ \\
\hline $11 \mathrm{Me}$ & $146 / 91$ & $-11 /+11$ & $-10 /-4$ & 0 & $1+$ & 0 & 0 & 0 & 0 \\
\hline $12 \mathrm{Cl}$ & $199 / 107$ & $+1 /+8$ & $-33 /-7$ & 0 & 0 & 0 & 0 & 0 & $3+$ \\
\hline Mean & $173 / 106$ & $-25 /-9 \ddagger$ & $-30 /-15 \ddagger$ & 0.3 & 1.3 & 0.1 & 0.3 & 0.3 & 1.3 \\
\hline
\end{tabular}

Patients 4 and 6 received Aldactazide, two tablets daily, throughout the study. The remainder of the subjects took chlorthalidone (Hygroton), 50 mg. daily.

Cases are arranged according to decline in mean blood pressure after methyldopa.

*" $\mathrm{Me}$ " and " $\mathrm{Cl}$ " refer to those patients in whom the first drug administered was methyldopa or clonidine, respectively,

† Average of two readings on diuretic alone before and after one month of placebo administration.

$\ddagger$ value for significance (Student $\mathrm{t}$ test) $<0.01$ for systolic blood pressure change with both drugs and for diastolic blood pressure change with clonidine. The reduction in diastolic blood pressure with methyldopa was significant at the level of $p<0.02$. When the response to each drug was compared, differences were not significant.

time of each visit they were also asked to record any side effects of treatment and to grade them as mild $(1+)$, moderate $(2+)$, and severe $(3+)$. The patients were assigned by the clinic nurse according to a prearranged random selection into one of two treatment groups, which were to start on one or the other drug. Neither patient nor physician was informed concerning the medication being taken. At the first visit, placebo tablets resembling the first drug to be supplied were given to the patient in addition to the diuretic he had been taking. He was asked to return at one month for a second visit. The avcrage of these two outpatient blood pressures served as the "control" readings. The patient was then started on the predetermined drug according to a fixed schedule: one tablet three times a day for one month, then two tablets three times a day for the next two months. The tablets were either $0.1 \mathrm{mg}$. for clonidine or $250 \mathrm{mg}$. for methyldopa. Six patients were started on clonidine and 6 were started on methyl- dopa first. After 3 months on the first medication, the subjects were changed to the other drug, repeating the dosage schedule noted above. An unaltered dose of a diuretic was continued throughout the study including the control period.

\section{Results}

Comparative effects on blood pressure and pulse rate. The average control recumbent blood pressure readings on placebo plus diuretic for those patients who were to receive the two drugs was $173 / 106 \mathrm{~mm}$. $\mathrm{Hg}$ (Table I). There was a significant reduction in the blood pressure of $25 / 9 \mathrm{~mm}$. $\mathrm{Hg}$ after 3 months on methyldopa. These same patients exhibited a significant reduction of $30 / 15$ after a 3 month period on clonidine. When the data were analyzed according to which drug was given first, the results were substantially unaltered by the sequence of treatment. Recumbent pulse rates declined from a control of 85 to 80 and to 68 on methyldopa and clonidine, respectively. 
Table II. Effect of clonidine and methyldopa on blood pressure $(B P)$ determined at home*

\begin{tabular}{l|c|c|c}
\hline & & Change in BP (mm. Hg) \\
Position & $\begin{array}{c}\text { Control BP } \\
(m m . H g)\end{array}$ & Methyldopa & Clonidine \\
\hline Lying & $168 / 109$ & $-25 /-20$ & $-32 /-21$ \\
Standing & $160 / 115$ & $-31 /-31$ & $-33 /-17$ \\
\hline
\end{tabular}

*Average of 5 days home blood pressure after 3 months of treatment on each drug.

These changes were of borderline significance for methyldopa $(p<0.05)$ and clearly significant for clonidine $(\mathrm{p}<$ 0.0001).

Inspection of Table I, which is arranged in order of blood pressure response to methyldopa, does not suggest that the decline in blood pressure was related to initial blood pressure. Those who responded well to one drug usually exhibited a similar response to the other. Thus Patients 1 through 7 who had generally good responses to methyldopa also had good blood pressure declines to clonidine, with two exceptions. Patients 9 and 10 had a possibly greater response to clonidine, but, in the other patients, nonresponse to both drugs was observed.

In an effort to determine whether the changes in blood pressure noted in the outpatient clinic were confirmed in the patient's daily life, the average of 5 days of morning home blood pressure readings taken immediately prior to the second outpatient visit was compared with readings over a similar period after 3 months on clonidine or methyldopa. Table II shows that a decline comparable to that seen with the clinic readings occurred in the blood pressure with the effects of clonidine again being slightly more prominent.

The lying-standing blood pressure gradient was equally affected by both drugs. The mean decline from lying to standing was: $-2 /+8$ (control); $-29 /-9$ (methyldopa); $-25 /-11$ (clonidine).

Comparison of side effects caused by each drug. Reference to Table I indicates that at the end of 3 months on each drug the patients taking clonidine experienced more side effects. This was true whether this drug was given in the first or second 3 month interval. The severity of sedation was generally classified as mild $(1+)$ in the majority of individuals taking clonidine; only 2 patients on this medication reported no sedation at the end of 3 months of therapy. In one instance, methyldopa produced more drowsiness than clonidine but in general this form of therapy did not produce recognizable drowsiness.

Constipation was not a problem in any of the subjects on either drug except in Patient 9, who complained of moderately severe constipation with clonidine. Occasional laxative usage was, however, more frequent among clonidine-treated patients.

Dry mouth was troublesome during clonidine administration, being reported as severe $(3+)$ or moderately severe $(2+)$ in 6 of the 12 patients. Three patients on methyldopa occasionally reported this as a minor complaint.

When patients are chosen with an approximately equal blood pressure response to both drugs (Patients 1 through 4), it is apparent that clonidine produced definitely more side effects than methyldopa. There was no definite correlation between blood pressure decline and severity of side effects on either medication.

Although in general methyldopa proved superior with respect to side effects, some additional comments should be made. In addition to Patient 4 who experienced more sedation on methyldopa, two individuals (not in the tables) had to be dropped from the study because of specific intolerance to this drug as exhibited by marked nausea and vomiting. These same patients exhibited a good blood pressure fall without gastrointestinal side effects on chronic clonidine therapy.

Orthostatic dizziness was not reported except in one patient (No. 4) who complained of this symptom while on methyldopa and with a recorded standing blood pressure of $137 / 82$ and a similar home blood pressure reading. On clonidine, with a lower upright blood pressure, this symptom was not reported.

\section{Discussion}

The above study demonstrates the approximately equal antihypertensive effectiveness of $1,500 \mathrm{mg}$. of methyldopa and 
$0.6 \mathrm{mg}$. of clonidine daily when a diuretic is concomitantly administered. The changes were manifest both in the outpatient and in the home blood pressure records and the effects were sustained for a period of 3 months. Our own experience with clonidine $^{3,4}$ and that of others ${ }^{5-12}$ suggests that late tolerance to the blood pressure lowering effects of these agents is not seen, particularly when a diuretic is concomitantly administered. Hence, it may be assumed that both drugs may be used effectively in long-term treatment of hypertension.

The site of action of methyldopa is not well established. The observation that certain patients responded equally to clonidine and to alpha methyldopa, while others were unresponsive to either medication, might suggest a common site of action for both these agents. To strengthen this hypothesis, we have previously observed that patients taking clonidine have less than the expected response to the addition of methyldopa. ${ }^{4}$ Furthermore, the latter drug, like clonidine, exerts an antihypertensive effect when given in small doses into the vertebral artery of experimental animals. ${ }^{13}$ There is, therefore, some circumstantial evidence that both drugs may act on a similar site in the central nervous system.

At equally effective doses, clonidine caused quantitatively more disability than methyldopa. Sedation occurred with both drugs, but more frequently and to a more marked degree with clonidine. However, this side effect was reported by the patients for brief transient periods each day and was apparent only when there was nothing to attract their attention; it did not interfere with the individual's capacity to work or to think. This modest disability may be relieved by methylphenidate (Ritalin), as we have reported elsewhere. ${ }^{4}$

Dry mouth was more prominent in patients taking clonidine. The side effect was bothersome but could be partially relieved by chewing gum or by fruit drops held in the mouth. Constipation appeared to be only a minor problem at this dose level, but was more evident with clonidine than with methyldopa.

Thus, while side effects were more frequent with clonidine, they were quite tolerable and no patients refused to continue taking the drug.
Other investigators have compared clonidine and methyldopa, usually under less precise circumstances. They have drawn similar conclusions. ${ }^{5,14-17}$

Seedat and co-authors ${ }^{15}$ reported on 30 patients receiving over 6 to 8 months' sufficient doses of each drug consecutively to reach a blood pressure level of $160 / 100$ or less. It required an average dose of 916 $\mathrm{mg}$. of methyldopa and $0.86 \mathrm{mg}$. of clonidine to achieve this effect. There were fewer side effects among those taking methyldopa. Two patients were unable to tolerate clonidine therapy. The authors conclude that methyldopa is a more acceptable antihypertensive drug under these conditions.

Finnerty ${ }^{16}$ has reported a study more comparable to ours in that chlorthalidone was administered as background medication and 30 patients were carried through 12 weeks of methyldopa and clonidine in random order. The drugs, given to achieve "an optimal effect on the blood pressure," averaged $960 \mathrm{mg}$. of Aldomet and $0.61 \mathrm{mg}$. of Catapres. Equal declines in mean blood pressure were observed, -17 and $-19 \mathrm{~mm}$. $\mathrm{Hg}$, respectively. In no instance was therapy discontinued because of side effects, which were considered by the author to be inconsequential at the third month. He reported the drowsiness to have been greatly reduced with the passage of time, an observation in which we concur.

Amery and associates ${ }^{17}$ gave to 41 patients already taking chlorthalidone, clonidine and methyldopa alternately, in doses adjusted to achieve an equal depressor effect at the end of 3 months. They estimated the response to $0.7 \mathrm{mg}$. of clonidine to be equal to $1,000 \mathrm{mg}$. of methyldopa. Although no attempt was made at quantitation of side effects, they were definitely more frequent with clonidine. They concluded that methyldopa would be the preferred drug, but also remarked on the greater depressor effectiveness of clonidine when both drugs were given in higher dosage.

If methyldopa produces the same blood pressure reduction with lesser side effects, the question is raised as to the clinical usefulness of the new agent except in cases of intolerance to methyldopa. Our own 
experience, reported previously, ${ }^{4}$ indicates that clonidine, in larger doses than the 0.6 mg. used in this study, has a greater depressor action, while it is generally accepted that raising the daily dose of methyldopa above the $1,500 \mathrm{mg}$. level is not usually accompanied by a significant further blood pressure reduction. Thus, by giving up to $2.4 \mathrm{mg}$. of clonidine daily, we were able to maintain a significant blood pressure reduction in severely hypertensive patients who had proven refractory to methyldopa or to guanethidine. The side effects were less severe than with the latter drugs. It is our opinion that clonidine will find a useful place in the treatment of those patients who do not respond satisfactorily to the use of a diuretic and methyldopa and that it will prove superior to guanethidine which is the chief present alternative in the management of severe hypertension.

\section{Summary and conclusions}

In order to compare the relative efficacy of methyldopa with the new antihypertensive drug, clonidine hydrochloride, a singleblind crossover study was utilized. After a control period, moderately hypertensive patients received fixed doses of each drug for one month followed by a double dose in the second and third month of observation, a diuretic being used throughout the study. The blood pressure response and the side effects produced at the end of 3 months of therapy were then compared. Clonidine (Catapres), $0.2 \mathrm{mg}$. 3 times daily, had a similar blood pressure reducing effect as $1,500 \mathrm{mg}$. of methyldopa given in a similar fashion. Blood pressure reduction averaged $25 / 9$ and $30 / 15 \mathrm{~mm} . \mathrm{Hg}$, respectively, with slightly more patients exhibiting significant blood pressure reductions on clonidine. This drug also reduced pulse rate and caused mild sedation and dry mouth, side effects rarely observed with methyldopa. 'Two patients, intolerant to the latter agent, were treated successfully with clonidine. Significant orthostatic hypotension was not observed with either drug.

Clonidine hydrochloride (Catapres) was supplied through the kindness of Dr. Paul Kennedy, Geigy Pharmaceuticals, Yonkers, N. Y.

The use of the facilities of the Upjohn Center for Clinical Pharmacology, University of Michigan Medical Center, is gratefully recognized.

\section{REFERENCES}

1. Kobinger, W.: The mechanism of action of a new antihypertensive substance with an imidazoline structure, Naunyn Schmiedebergs Arch. Pharmakol. Exp. Path. 258:48, 1967.

2. Sattler, R. W., and Van Zwieten, P. A.: Acute hypotensive action of 2-(2,6-dichlorophenylamino)-2-imidazoline hydrochloride (S' 155) after infusion into the cat's vertebral artery, Eur. J. Pharmacol. 2:9, 1967.

3. Smet, G., Hoobler, S. W., Sanbar, S., and Julius, S.: Clinical observations on a new antihypertensive drug, 2-(2,6-dichlorphenylamine)-2imidazoline hydrochloride, Au. HEART J. $77: 473,1969$.

4. Hoobler, S. W., and Sagastume, E.: Clonidine hydrochloride (Catapres) in the treatment of hypertension, Am. J. Cardiol. 28:67, 1971.

5. Bock, K. D., Heimsoth, V., Merguet, P., et al.: Klinische und klinisch-experimentelle Untersuchungen mit neuen blutdrucksenkenden substanz: dichlorphenylaminoimidazolin, Dtsch. Med. Wochenschr. 91:1761, 1966.

6. Jungling, K.: Klinische untersuchungen mit dem neuen antihypertonikum Catapresan, Die Medizin. Welt 19:2105, 1968.

7. Raftos, J.: The use of "Catapres" in the treatment of severe hypertension, Med. J. Aust. 2:684, 1969.

8. Onesti, G., Schwartz, A. B., Kim, K. E., Swartz, C., and Brest, A. N.: Pharmacodynamic effects of a new antihypertensive drug, Catapres (ST 155), Circulation 39:219, 1969.

9. Gifford, R. W., Jr.: Clonidine in the management of mild hypertension in 22 patients, Cleve. Clin. Q. 36:173, 1969.

10. Kellett, R. J., and Hamilton, M.: The treatnent of benigin hypertension with clonidine, Scott. Med. J. 15:137, 1970.

11. Khan, A., Camel, G., and Perry, H. M., Jr.: Clunidine (Catapres): A new antihypertensive agent, Curr. Ther. Res. 12:10, 1970.

12. MacDougall, A. I.: Treatment of hypertension with clonidine, Br. Med. J. 3:440, 1970.

13. Henning, M., and Van Zwieten, P. A.: Central hypotensive effect of methyldopa, J. Pharm. Pharmacol. 20:409, 1968.

14. Conolly, M. E., Paterson, J. W., and Dollery, C. T.: A comparative trial of Catapres and methyldopa, in Conolly, M. E., cditor: Catapres in hypertension (a symposium), London, 1970, Butterworth \& Co. (Publishers) Ltd., p. 167.

15. Secdat, Y. K., Vawda, E. I., Mitha, S., Ramasar, S., and Ramasar, R.: A comparison of alpha-methyldopa (Aldomet) and ST155 (Catapres) in the treatment of hypertension, S. Afr. Med. J. 44:300, 1970.

16. Finnerty, F. A., Jr.: Evaluation of the antihypertensive effects of Catapres in man, in Conolly, M. E., editor: Catapres in hypertension (a symposium), London, 1970, Butterworth \& Co. (Publishers) T.td., p. 155.

17. Amery, A., Verstraete, M., Bossaert, H., and Ver Streken, G.: Hypotensive action and side effects of clonidine-chlorthalidone and methyldopa-chlorthalidone in treatment of hypertension, Br. Med. J. 4:392, 1970. 